\title{
LA CRISIS DEL SISTEMA HACENDAL. REPRESENTACIONES EN LA NARRATIVA DE MUJERES (1930-1965).
}

\author{
Ana Traverso" \\ Universidad Austral de Chile
}

Durante la primera mitad de siglo las mujeres se van incorporando paulatinamente al mundo del trabajo y las intelectuales, llegan a ocupar diversos espacios en el circuito de la cultura y el arte. Sin embargo, estas aparentes conquistas de los movimientos sociales y feministas en el continente, son significados en los relatos de gran parte de las escritoras chilenas en tanto pérdida de los privilegios oligárquicos del ocio y la cultura, que las ubica en una tensionada relación entre la nostalgia patriarcal (tras la crisis del latifundio), la ansiada (u obligada) independencia económica y la crítica a la precarización y disciplinamiento del mundo del trabajo. Me interesa analizar las significancias que cobra la «escritura» para estas autoras en el entrecruce entre la obtención del «cuarto propio» y la (in)dependencia de género.

Palabras Claves: Hacienda-escritoras chilenas-trabajo-autonomía-escritura

THE CRISIS IN THE RANCH SYSTEM. PRESENCE IN WOMEN'S NARRATIVE (1930-1965)

During the first half of the XX century women enter gradually in the world of work. Female intellectuals obtain positions in the realm of culture and art. These are real advances brought about by social and feminist movements in the whole continent. Nevertheless there are underplayed in the narratives of an important part of Chilean female writers and presented as a loss of leisure and culture those oligarchic privileges. So their works show a tense relationship between the nostalgia of patriarchalism (after the crisis of the large estate), the eagerness for economic independence (or the inevitability of it) and also the criticism face to the workers having their jobs made precarious and also the disciplining of labor. I am interested in analyzing the new meaning that «writing» acquires for these writers in the mixture of obtaining an «own room» with gender (in)dependence.

Keywords: hacienda-Chilean females writers-work-autonomy-writing

Artículo Recibido: 20 de Noviembre de 2018

Artículo Aceptado: 13 de Marzo de 2018

- Este artículo forma parte de los resultados del proyecto Fondecyt Regular 1150667, «Escritura, histerización y violencia: las autoras en el Chile de mediados del siglo XX (1930-1970)».

. E-Mail: anatraverso@gmail.com 


\section{Presentación}

as escritoras chilenas que comienzan a publicar entre los años 30 y los 50 lo
hacen a partir de una serie de cambios sociales que permiten su incorporación a
la escena pública: las reformas estatales (como los proyectos de ley sobre
ciudadanía política, derecho a educación, trabajo, entre otros), la militancia política feminista activa (liderando comisiones y partidos) ${ }^{1}$, la participación en los variados ámbitos de la cultura y la educación ${ }^{2}$; todo lo cual, para mediados de siglo, ha contribuido a que cuenten con una producción literaria prolífica y exitosa y, tal como afirma Darcie Doll,

\footnotetext{
${ }^{1}$ Siguiendo a Lavrín, Asunción, Mujeres, feminismo y cambio social en Argentina, Chile y Uruguay 1890-1940, Centro de Investigación Diego Barros Arana, Santiago, 2005, quisiera precisar que las autoras que se instalan más profesionalmente en el oficio a partir de los años '30 -y que aquí analizamos- difieren de sus antecesoras Delia Rojas (Delie Rouge), Elvira Santa Cruz Ossa (Roxane), Inés Echeverría (Iris), entre otras, en precisamente su postura respecto al movimiento feminista. Si sus precursoras respondieron positivamente a las demandas del movimiento en temas como el divorcio, el derecho a voto o la educación femenina, las que le siguen tendieron a ser más cautas o descreídas respecto de creer que estas demandas podrían solucionar los problemas de las mujeres. Para profundizar en estas diferencias generacionales sugiero revisar el trabajo de Kottow, Andrea, «Feminismo y femineidad: escritura y género en las primeras escritoras feministas en Chile», Atenea, $\mathrm{n}^{\circ}$ 508, 2013 (pp. 151-169) que aborda las primeras escritoras feministas chilenas.

${ }^{2}$ En un manuscrito actualmente en evaluación, desarrollo la representación en las novelas de estas escritoras respecto del trabajo y el oficio literario. De acuerdo a la interpretación de Hutchison sobre las cifras del censo, vid. Hutchison, Elizabeth, «La historia detrás de las cifras: la evolución del censo chileno y la representación del trabajo femenino, 1895-1930», Historia, $\mathrm{n}^{\circ} 33,2000$ (pp. 417-434), y su propuesta de un aumento de la participación femenina en el mercado laboral para mediados de siglo, vid. idem. y a Hutchison, Elizabeth, Labores propias de su sexo. Género, políticas y trabajo en Chile urbano 1900-1930, LOM, Santiago, 2006, las novelas (y también las prácticas de las autoras) van mostrando que muchas de sus protagonistas se ven obligadas a trabajar producto de la crisis del sistema hacendal, aunque sin contar ni con educación suficiente ni menos con una profesión que ejercer. Conforme al proceso de desarrollo de la educación primaria en Chile, vid. Egaña, María Loreto; Núñez Prieto, Iván y Salinas Álvarez, Cecilia, La educación primaria en Chile: 1860-1930. Una aventura de niñas y maestras, LOM-PIIE, Santiago, 2003, y el avance de un estado benefactor dispuesto a mejorar las condiciones educativas de los sectores medios y bajos, las mujeres de la elite reclaman poseer inferiores niveles educativos que la clase media, sin más posibilidad que desarrollar labores de secretariado, dactilografía, costura, educativas, y sin contar por cierto con títulos profesionales más que el de «asesora del hogar», como le gusta decir a Maité Allamand en su autobiografía literaria, vid. Allamand, Maité, Quién soy, Editorial Nascimento, Santiago, 1982. Obligadas a incorporarse al mundo laboral por motivo de «descenso social» y/o «falla del hombre», vid. Lavrín, Asunción, op. cit., p. 78, el trabajo femenino aparece en estas novelas asociado -según el discurso de la época y tal como lo señalan Godoy, Díaz y Mauro - con un fuerte componente de clase, es decir, "como una necesidad a la que se veían enfrentadas aquellas mujeres de sectores populares por la falta de protección masculina de padres y esposos. De este modo, el sentido del trabajo en el caso de mujeres que ejercían una profesión no fue materia de discusión, el aumento de profesoras y preceptoras, de matronas y parteras, médicas, enfermeras y practicantes no modificó la visión predominante que concibió el trabajo como una realidad más propia de mujeres populares», Godoy Catalán, Lorena; Díaz Berr, Ximena, y Mauro Cardarelli, Amalia, «Imágenes sobre el trabajo femenino en Chile, 1880-2000», Universum, n²4, 2, 2009 (pp. 74-93).
}

INTUS-LEGERE HISTORIA/ ISSN 0718-5456| EISSN 0719-8949/Año 2018, Vol. 12, N¹, pp. 45-65. 
hayan logrado consagrarse como «profesionales» del oficio ${ }^{3}$. No obstante, al mismo tiempo que las intelectuales van haciéndose un lugar en el espacio público-como editoras, columnistas, miembros de jurado y directoras de organizaciones culturales-, sus novelas tienden a situar a la mujer cada vez más alejada de los espacios de representación, en una situación de encierro e inmovilidad, que les impide cualquier tipo de toma de decisión ${ }^{4}$.

El encierro que padecen los personajes de estas novelas es una situación sintomática que se observa tanto en la ciudad, el campo, como en la relación campo ciudad, ilustrando de este modo el vínculo económico que la oligarquía mantenía con ambos territorios: la ciudad para la educación de los hijos y el desarrollo de la política y los negocios; el campo para veranear y ostentar el lugar de privilegio que todavía seguía gozando la clase terrateniente ${ }^{5}$. La preferencia, representación y relación que las escritoras oligarcas ${ }^{6}$ hacen de ambos espacios, varía en las distintas novelas, pero, sobre todo, responde de muy diverso modo a la pregunta por la autonomía al situarse en uno u otro lugar. Así, cuando Natalia Cisterna se propone analizar la relación casa/ciudad en las narradoras latinoamericanas de la primera mitad del siglo XX7 ${ }^{7}$, el cuestionamiento por la emancipación en la relación cronotópica urbana atiende a asuntos vinculados con la vocación, las condiciones laborales, y la difícil y compleja inserción como bien lo demuestra Cisterna en el espacio público. Preguntarse en cambio por la autonomía de las mujeres en el «cronotopo» «campo»o «hacienda» pone el énfasis en otra argumentación: ya no interesará sólo su inserción en el espacio público, sino (y, sobre todo) la explicación sobre el origen del sistema patriarcal y sus modos de pervivencia en la sociedad de la época, así como la inclusión/exclusión de las mujeres en los sistemas de subordinación y explotación social.

\footnotetext{
${ }^{3}$ Doll, Darcie, «Escritoras chilenas de la primera mitad del siglo XX: trayectoria en el campo literario y cultural como criterios para una periodización de su producción», Taller de Letras, n 54, 2014 (pp. 23-38).

${ }^{4}$ Sigo la tesis de Julieta Kirkwood, quien plantea que con la obtención del voto femenino se produce un repliegue en el movimiento feminista chileno, en tanto las mujeres se incorporaron a los partidos tradicionales y asumieron que el "objetivo mujer» se había resuelto, produciéndose con ello una especie de «silencio feminista», vid. Kirwood, Julieta, Ser política en Chile. Las feministas y los partidos (1986), Editorial Cuarto Propio, Santiago, 1990. Este silencio es inversamente proporcional a la cantidad de novelas que publican las mujeres en los años '50, donde «lo femenino» y «la mujer» serán el centro de interés, proponiendo asimismo su ausencia de los espacios de representación. Asimismo, tanto Kottow como Olea vinculan la producción de escritoras del 50 con este llamado «silencio feminista», vid. Kottow, Andrea, «Feminismo y femineidad: escritura y género en las primeras escritoras feministas en Chile», Atenea, $n^{\circ}$ 508, 2013 (pp. 151-169), Olea, Raquel, «Escritoras de la generación del cincuenta. Claves para una lectura política», Universum, $n^{\circ} 25,2010$ (pp. 101-116). Muy pocas, dice Kirkwood, «harán de la mujer el objeto de su inquietud o preocupación política e intelectual», Kirkwood, Julieta, op. cit., p. 182, alimentando «la sensación de que no existía tal problema femenino», ibidem, p. 183. Con ello, quedan relegadas de los «espacios de representación como sujeto social, sin organizaciones, con escasos derechos laborales y de salud, sin derechos culturales ni comunicacionales, sin lugares de enunciación, para elaborar discursos y demandas»: «al arbitrio del orden tradicional de género», Olea, Raquel, op. cit., p. 110.

${ }^{5}$ Respecto a los modos de vida de la aristocracia chilena de la época, sugiero revisar el iluminador estudio de Barros, Luis y Vergara, Ximena, El modo de ser aristocrático. El caso de la oligarquía chilena hacia 1900 (1978), Ariadna Ediciones, Santiago, 2007.

${ }^{6}$ Origen social de la gran mayoría de las autoras de la época.

${ }^{7}$ Cisterna, Natalia, Entre la casa y la ciudad. La representación de los espacios público y privado en novelas de narradoras latinoamericanas de la primera mitad del siglo XX, Editorial Cuarto Propio, Santiago, 2016.
} 
En este sentido, nos parece ver en los relatos de «hacienda» (de autoras que escriben entre los 30 y los 70) una suerte de explicación sobre la situación de sometimiento y/o autonomía de la mujer. Muchas de estas novelas organizan la genealogía de las protagonistas a partir de la destrucción del modelo hacendal, que define su entrada al mundo del trabajo y a la escritura. Sin embargo, esa gran transformación se entiende en tanto «desheredadas» o, más aun, como «expulsadas de un paraíso» que no sólo se asocia a la pérdida de los privilegios oligárquicos, sino a la «culpa» que genera esta expulsión. La relación entre la estructura económica del latifundio y el relato cristiano, entraña los pilares más gruesos que estas autoras visualizan como causa de su nueva condición de mujeres arrojadas al mundo del trabajo: sin las protecciones sociales, sin educación profesional, sin la validación de sus pares, la mujer vendría a ser la gran perdedora de las conquistas obtenidas por los movimientos sociales del s. XX. De este modo, estos relatos constituyen una crítica a los procesos democratizadores, donde los beneficiados continuarían siendo los varones - ahora, los de la clase media y, a partir de las políticas de reforma agraria, la paulatina consideración hacia el campesinado , mientras las mujeres proseguirían al margen de la agenda política. Porque la inclusión de las mujeres no se lograría sólo con un programa económico, legislativo y educativo, parecen decirnos estos relatos, sino con una renovación en materia de género, dispuesta a repensar los valores cristianos en torno a la diferencia.

El corpus de novelas (y algunos cuentos) de hacienda se compone de una larga lista constituida por textos como: El abrazo de la tierra (1933), Espejo sin imagen (1936), Las cenizas (1942), ¿Dónde están el trigo y el vino? (1962) de María Flora Yáñez; Cosas de campo (1935), Parvas viejas (1936) de Maite Allamand; Tía Eulalia (1950) de Chela Reyes; La culpa (1964) de Margarita Aguirre; Páramo Salvaje (1963) de María Elena Gertner; y La tierra que les di (1963) de Mercedes Valdivieso, por nombrar solo algunas. Publicadas entre las décadas del' 30 y del ' 60 , se enmarcan en el periodo de crisis del latifundio tras la caída del salitre (1914), la gran depresión de 1929 y el comienzo de los primeros amotinamientos campesinos. Son unos largos treinta años en que se inician las discusiones sobre la propiedad de la tierra y la necesidad de acceder a ella por parte de los trabajadores, desde la formación del Frente Popular (1938) hasta las leyes de Reforma Agraria (1962 1973).

INTUS-LEGERE HISTORIA/ ISSN 0718-5456| EISSN 0719-8949/Año 2018, Vol. 12, N¹, pp. 45-65. 


\section{La crisis de la hacienda}

José Bengoa ${ }^{8}$ estudia y analiza detenidamente la huelga que se produce el año 1921 en el fundo «Lo Herrera», de propiedad de Eleodoro Yáñez ${ }^{9}$, por ser el primer caso mediático de «protesta campesina» que es reportado por la prensa y, junto con ello, por ser la primera vez que aparece la «voz del inquilino» en los medios. Los hechos se desencadenaron a causa de la expulsión de un trabajador y su familia, suscitando la preocupación del dirigente secretario general de la Junta Provincial de la FOCH (Federación Obrera de Chile) y del periodista del diario La Federación Obrera, quienes organizan una visita al fundo con el fin de conocer las condiciones de los trabajadores. Se genera así un pliego de peticiones por parte de los campesinos, que es aceptado en su mayor parte por la jefatura, y una Comisión Permanente de inquilinos, encargada de velar por las condiciones laborales. Intentan negociar con la administración la reposición del inquilino expulsado, y ante la negativa de ésta, la comisión viaja varias veces a Santiago para entrevistarse personalmente con el dueño. A pesar de que el senador Yáñez termina yendo al fundo (un terreno de 3.278 hectáreas en la actual zona de San Bernardo), quienes se entrevistan con los campesinos serán su administrador, Ramón Alzérreca, y su yerno, el señor Rafael Echeverría Larraín, informándoles que les quitarán las garantías pactadas anteriormente. Ingresa carabineros al fundo, persiguen a los trabajadores hasta sus casas, los golpean, maltratan a sus mujeres e hijos, y terminan siendo despedidos y expulsados de la hacienda. Yañez finaliza el conflicto con la publicación de un largo informe en el diario EI Mercurio, donde desarrolla la idea de la inoculación de «agitadores» foráneos en los campos chilenos. Recalca Bengoa que se trata del «primer hecho de protesta político social en el país, [en que] surge la idea de los 'agitadores'. El campo vive tranquilo, señalan subrepticiamente los propietarios, y son personas de fuera del campo, de la ciudad «de Santiago», quienes vienen a sublevar a los buenos campesinos» ${ }^{10}$. Este discurso pauteará «la tónica del siglo XX» ${ }^{11}$.

Me he extendido en describir este caso que relata Bengoa, no sólo porque sitúa el conflicto del agro en los comienzos de la década del '20, sino porque explica la preocupación que María Flora Yáñez, hija del político, manifiesta por la distribución y administración de la tierra en al menos tres de sus novelas: El abrazo de la tierra (1933), Espejo sin imagen (1936), Dónde está el trigo y el vino? (1962) ${ }^{12}$. El énfasis que le dará la escritora al hecho tiene -a mi juicio dos sentidos, el de mostrar la necesidad de la modernización que requerirían los campos chilenos, y el de denunciar la pérdida de liderazgo de la oligarquía terrateniente, generada entre otras razones por la ausencia del patrón en los fundos. Si bien la crisis del sistema

\footnotetext{
${ }^{8}$ Bengoa, José, Historia Rural de Chile central. Tomo 1 y 2, Editorial LOM, Santiago, 2015.

${ }^{9}$ En esa época, Eleodoro Yáñez era senador por la Alianza Liberal y Presidente de la Liga Chilena de Higiene Social, además de fundador del diario La Nación.

${ }^{10}$ Bengoa, José, op. cit., p. 28.

${ }^{11}$ Idem.

${ }^{12}$ De las novelas de Flora Yáñez (o Mari Yan), la mayor parte está ambientada en la hacienda chilena, ubicada en la zona central del país. Es el caso de El abrazo de la tierra (1933), su primera novela, Espejo sin imagen (1936), Las cenizas (1942), La piedra (1952), y Dónde está el trigo y el vino? (1962). Solo tres de ellas se desarrollan en la ciudad de Santiago: Mundo en sombras (1935), El último faro (1967) y El peldaño (1974).
} 
hacendal obedece a motivos más complejos que los que presenta María Flora Yáñez en sus novelas ${ }^{13}$, me interesa analizar el discurso que ella y las restantes novelistas articulan en torno a este conflicto, pareciendo sugerir que el «vacío» que se origina en la cúpula del sistema hacendal con esta crisis, le permitiría a la escritora tomarse la palabra para representarlo ${ }^{14}$. Este pensamiento se asienta -siguiendo la tesis de Oscar Oszlak - en el discurso que erigió la oligarquía para defender el sistema tradicional del latifundio y que comienza a 'hacer aguas' en

${ }^{13}$ Hacia mediados del S. XIX el sistema hacendal se encontraba consolidado en Chile, configurando un poder económico y político que se encarnaría en la figura del Estado Oligarca, vid. Mellafe, Rodolfo, «Latifundio y poder rural en Chile de los siglos XVII y XVIII», Cuadernos de Historia, n 1, 1981 (pp. 87-108); Chonchol, Jacques, Sistemas agrarios en América Latina. De la etapa prehistórica a la modernización conservadora, Fondo de Cultura Económica, Santiago, 1996. Este poder logra fortalecerse a través de la expansión de la explotación agrícola nacional durante el periodo 1850 a 1875, producto de la demanda que generó la explotación de oro en California desde 1845, transformándose en la época de oro de la actividad cerealera chilena, según indica Jacques Chonchol: «Las exportaciones chilenas llegaron a su punto más alto, multiplicándose por seis entre 1846-50, en que Chile exportó 250 mil toneladas de trigo y harina en promedio anual, y en 1871-1875, en que exportó alrededor de un millón y medio de toneladas anuales», Chonchol, op. cit., p. 168. El impacto que tuvo este proceso en el sistema agrario nacional, sumado a la imposibilidad de iniciar tempranamente procesos de industrialización, permite comprender las desigualdades y el llamado "atraso del sistema de haciendas», Kay, Cristóbal, «Política Económica, Alianza de Clases y Cambios Agrarios en Chile», Economía, n 3, 5, 1980 (pp. 125160), p. 131. La pérdida del poder de la Oligarquía-Terrateniente dentro del estado -que fue hegemónico hasta 1920 producto del dominio sobre la tierra y su alianza estratégica con el capital inglés-, se inicia con la expansión del obrerismo y el agotamiento de un modelo de ejercicio del poder, al plantearse la necesidad de redefinir el papel del estado, tendiente a incorporar la política social como mecanismo para apaciguar la conflictividad popular, Illanes, María Angélica, Cuerpo y sangre de la política. La construcción histórica de las Visitadoras Sociales (1887-1940), LOM, Santiago, 2006. Esta pérdida de legitimidad de la clase política oligárquica produjo una división al interior del mismo sector y respecto a los grupos «ligados a la industria, la minería y las finanzas», quienes «comienzan a actuar en forma más independiente, conjuntamente con los empresarios emergentes en estas actividades, Cereceda, Luz Eugenia y Dahse, Fernando, Dos décadas de cambios en el agro chileno, Alfabeta impresores, Santiago, 1980, p. 24. Es así como surge una coyuntura que hace posible el planteamiento de un nuevo proyecto de desarrollo, basado fundamentalmente en la industrialización", en idem. Junto con lo anterior, la crisis del '29 bajo un modelo económico en extremo dependiente impactará directamente en la economía nacional, golpeando así duramente la agricultura, vid. Gómez, Sergio y Echeñique, Jorge, La Agricultura Chilena: las dos caras de la modernización, Ed. Flacso/Agraria, Santiago, 1988, p. 42, lo cual sumado a la contracción de la demanda interna agravan más aún la situación financiera de los fundos y haciendas. Lo señalado da cuenta de un proceso que configura un momento histórico de crisis del poder hacendal y sus expresiones económicas, políticas y culturales que transforman las estructuras sociales del país y las trayectorias históricas del trabajo, Salazar, Gabriel, Labradores, peones y proletario, LOM, Santiago, 2000.

${ }^{14}$ Si bien para la historiografía las novelas de época han sido una fuente productiva de información -pienso en los trabajos de Bengoa, Valdés et al, Barros y Vergara, entre otros-, el foco que estos autores han puesto en la narrativa escrita por varones ha contribuido a fortalecer la imagen de la mujer del terrateniente en tanto figura pasiva, al menos, en el espacio de la hacienda. Me parece que el análisis de la producción literaria de autoras mujeres, más que contraponer esa representación, contribuye a darle voz (y sensibilidad) a una actora poco presente en los relatos masculinos. Pues, tal como indican Valdés, Rebolledo y Wilson, «las mujeres de los hacendados tienen menos relevancia en las fuentes escritas, figurando como silenciosos personajes que callan frente a las diversiones del marido con otras mujeres, o como seres dispendiosos que prefieren vivir en la ciudad para estar al tanto de la moda y desplegar la sociabilidad en los salones citadinos. Otras son recreadas trabajando de sol a sol cuando el acceso a la tierra por parte de sus maridos ha sido dificultoso, o cuando se trata de mujeres viudas. Al lado de las figuras masculinas de su clase, estas mujeres aparecen apenas esbozadas y con contornos más bien borrosos», Valdés, Ximena; Rebolledo, Loreto y Wilson, Angélica, Masculino y femenino en la hacienda chilena del siglo XX, Fondart, Santiago, 1995, p. 61. 
las primeras décadas del s. XX, al evidenciar un progresivo estancamiento económico en el país. Afirma Oszlak:

Los propietarios de grandes extensiones mantenían, por lo general, técnicas de cultivo tradicionales y reinvertían sus ganancias en negocios, industrias y otras actividades urbanas más fáciles de controlar, menos riesgosas y más rentables (...). Además, a medida que crecía la población, el valor de sus tierras crecía gradualmente, reforzando su privilegiada posición. La falta de progreso en la agricultura podia, entonces, explicarse por la estructura de propiedad y tenencia que, paradójicamente, ponía el control de la tierra en manos de aquellos que o bien no tenían la motivación o los recursos para emplearlas productivamente ${ }^{15}$.

Esta situación irá instalando a los terratenientes como el sector responsable del estancamiento agrario, perdiendo así prestigio y legitimidad social frente a la opinión pública. El estudio de Oszlak busca entonces analizar lo que llama «trama oculta del poder», para dilucidar el comportamiento político que los terratenientes chilenos desplegaron ante la inminente crisis del agro y que dilató la promulgación de la reforma agraria hasta adentrados los años '60.

Las posturas se dividieron en dos grandes grupos, según Oszlak: los 'agraristas' (minifundistas, medieros, arrendatarios y trabajadores sin tierra), quienes estaban a favor de transformar la estructura social agraria y los derechos de propiedad, apoyando una redistribución más equitativa de la tierra (la división y repartición a los trabajadores); y los 'ruralistas' (grandes y medianos terratenientes), que trasladaban el énfasis del hombre a la técnica, al tratar de promover la innovación tecnológica y el incremento de la producción y, paralelamente, seguir manteniendo las condiciones sociales existentes sin preocuparse por una distribución más equilibrada de la tierra ${ }^{16}$.

Las novelas de María Flora Yáñez (o Mari Yan), como veremos, se inclinan por los argumentos 'ruralistas', al focalizarse exclusivamente en las necesidades de una renovación de la infraestructura, minimizando el movimiento campesino o, al menos, atribuyéndolo a la falta de liderazgo y ausencia de los patrones.

\footnotetext{
${ }^{15}$ Oszlak, Oscar, La trama oculta del poder. Reforma agraria y comportamiento político de los terratenientes chilenos, 1958-1973, LOM-USACh, Santiago, 2016, p. 21.

${ }^{16}$ Frente a la cada vez más evidente crisis del agro, los terratenientes buscarán atribuirle la responsabilidad a factores como las condiciones desfavorables de los mercados externos, la falta de créditos y de precios remunerativos, la deficiencia en la aplicación de nuevas tecnologías, la inflación, los altos impuestos, las condiciones meteorológicas, etc., disimulando con ello el componente de lucha de clases y buscando el apoyo de grupos o instituciones que simpatizaran con su posición.
} 
El primer libro de Flora Yáñez, El abrazo de la tierra (1933), es en apariencia la historia de frustración y aburrimiento de una joven atada a una hacienda, que fantasea con amoríos hacia un delicado hombre de mundo, el cual se proyecta en sus deseos como aquel galán capaz de arrancarla de la rutina y el encierro. Nada de eso ocurre y, muy por el contrario, la novela termina de forma similar a La última niebla (1934) de María Luisa Bombal, con una protagonista mansamente resignada a unirse a un gerencial dueño de tierras: «Ahora para siempre... vas a dormir, a dormir...» ${ }^{17}$. Pero a este poderoso deseo de huir del campo -signado por valores coloniales, nobiliarios y anticuados , la ciudad tampoco se proyecta como una alternativa, en tanto representa para la joven el derroche de frivolidad y mal gusto de los nuevos ricos. Su apego pareciera estar entonces en la naturaleza y el paisaje de la zona central, aunque le irriten las tradiciones del latifundio, así como la omnipresencia de las costumbres religiosas en misiones, bautizos, fiestas patrias, matrimonios, etc., que dominan hasta los modos de producción de la tierra: el colmo para la muchacha es el exterminio de plagas con agua bendita que rocía el cura sobre los árboles infectados de la hacienda.

¿Se puede dejar tan fácilmente la tierra que conserva aún una palma «de cien, doscientos, tal vez trescientos años. Tan vieja era, que según decía la tradición, había visto llegar del norte del país, a aquellos huincas que vinieron a instalarse en el suelo sagrado de los indígenas» ${ }^{18}$ ? ¿Se puede dejar una casona, en donde aún penaba la que fuera «dueña del fundo allá en los tiempos de la colonia, una dama linajuda» ${ }^{19}$, de la cual si no eran directos herederos, los actuales patrones, conservaban el «abolengo» y la «cuna patricia»? El «abrazo de la tierra», que da título a la novela, parece resaltar el compromiso de la protagonista por un bien patrimonial que merece con urgencia una renovación. Aunque al margen del manejo de la tierra, la joven guarda un sentido interés por denunciar el atraso de las costumbres y de la producción de la hacienda, prácticas que vendrían replicándose de igual manera desde la conquista con los encomenderos y luego con los fundadores de la nación chilena. Pero así como critica su sistema productivo, se asienta en tanto legítima heredera de una tradición, modelada por los primeros «huincas», y difícilmente disputable por los nuevos grupos sociales de comienzos del siglo XX, que en ésta, su primera novela, no aparecen siquiera como posible amenaza del orden inmemorial del latifundio.

Será en Espejo sin imagen (1935), su segunda publicación, en que Mari Yan -a través de la voz de los profesionales y representada en el administrador y la maestra de la escuela del fundo , introduce el cuestionamiento a la propiedad y al sistema de organización social de la hacienda. El texto se centra en los dos personajes mencionados para dar cuenta de la producción de la tierra y de la realidad material y cultural de los campesinos. Clarisa, la joven maestra, ha elegido trabajar en lugar de tener una vida matrimonial por conveniencia. Sin ser bella ni demasiado inteligente (cualidades que nuestra autora parece reservar a las mujeres de

\footnotetext{
${ }^{17}$ Yáñez, María Flora, El abrazo de la tierra, Imprenta Universitaria, Santiago, 1933, p. 196.

${ }^{18}$ Ibidem, pp. 10-11.

${ }^{19}$ Ibidem, p. 11.
} 
alcurnia) es en cambio empática y sobre todo comprometida con el mundo social. Pronto se enamora del campo; pero no de aquellos jardines ornamentales cercanos a la casa patronal, sino del trabajo productivo: las lecherías, los embalses, los sistemas de riego, el vivero, los cultivos, y con ello, de su responsable, el administrador del fundo, don Reinaldo. Descubre muy rápidamente lo que el dueño ausente de la finca no le interesa ver: el esfuerzo de los trabajadores contra las pestes, sequías, heladas, plagas e inundaciones provenientes de la naturaleza. Se alarma al enterarse de las condiciones de explotación laboral, de los salarios ínfimos que reciben los campesinos, de las viviendas precarias y en malas condiciones higiénicas, además de las altas tasas de analfabetismo, tendencia al alcoholismo, abuso infantil y violencia intrafamiliar. Sin desmoralizarse, empero, se esfuerza diariamente en la escuela y en el «puerta a puerta» para que los menores asistan al colegio y no sean presionados a emplearse de «obligados» ${ }^{20}$. Finalmente irrumpe el movimiento campesino al interior de la hacienda y Reinaldo se ve de pronto defendiendo con pasión los beneficios de los patrones y, como ellos, apoyando la idea de la sedición externa: «los agitadores han dejado aquí un fermento de odio, de inquietud. Mis hombres no son los de antes. Desconfían, se creen explotados, no tienen fe» ${ }^{21}$. Es aquí donde el relato se vuelve una suerte de novela de tesis, al exponerse la argumentación a favor y en contra de un incremento en los salarios y de otorgar el derecho de propiedad a quien cultiva la tierra, en aras de solucionar los problemas expuestos. Clarisa en esta discusión se manifiesta a favor de todas estas reformas y de paso critica con elocuencia la ausencia del patrón en la gestión del campo. La serie de acontecimientos funestos que se desencadenan (el suicidio de Reinaldo, la infidelidad de su mujer con un carabinero, la muerte de un estudiante, la violación de una niña, hasta la amputación de los dedos de un trabajador con una máquina picadora) terminan por desalentar definitivamente a la joven maestra, quien finalmente opta por trasladarse a una escuela primaria en Linares.

Las conclusiones sobre el mundo del campo son evidentes. No hay una jefatura responsable, pues el campo ha llegado a ser para las elites terratenientes sólo un medio de obtención de ganancias. No se invierte en modernizar la infraestructura productiva ni hay preocupación por las condiciones humanas de los trabajadores. No se respetan las leyes impulsadas por el gobierno: la Ley 4054 del año 1924 sobre higiene y seguro de enfermedades para los trabajadores ${ }^{22}$, ni la Ley 3654 de 1920 sobre Educación Primaria Obligatoria ${ }^{23}$. Todo lo cual formula Clarisa, dando cuenta de su adhesión a las iniciativas del Estado para mejorar las condiciones laborales y sociales de los trabajadores y sus familias -en los términos

\footnotetext{
${ }^{20}$ Parte del contrato de un inquilino, suponía entre sus obligaciones, el aporte de la mano de obra de un trabajador adicional, llamado «obligado», según lo requiriera la demanda de la hacienda (cosechas, trabajo en «las casas»), lo cual podía cumplirlo cualquiera de los miembros de su familia: hijos, esposa o algún otro miembro.

${ }^{21}$ Yáñez, María Flora, Espejo sin imagen, Editorial Nascimento, Santiago, 1936, p. 79.

${ }^{22}$ Cfr. lbidem, p. 62.

${ }^{23}$ Ibidem, p. 15.
} 
asistenciales y moralizantes ${ }^{24}$ que están detrás de estas leyes , y avizora la posibilidad de entrar a discutir asuntos estructurales sobre la distribución de la tierra:

La propiedad debe ser colectiva. ¿Por qué estas tierras inmensas pertenecen a un hombre que no las trabaja, que apenas las conoce? Admita siquiera que la tierra, por derecho, es más de aquel que la fecunda, de aquel que la hace prosperar. ¿Qué valía esta hacienda cuando Ud. llegó? Muy poco. Y si hoy vale, es por el trabajo que en ella hay cristalizado ${ }^{25}$.

Me pregunto si la baja austoestima que padece Clarisa, quien se considera poco agraciada, incapaz de atraer al hombre que ama, no muy talentosa profesionalmente y, sobre todo, con una ostensible tendencia a subestimar las capacidades intelectuales de las educadoras $-\mathrm{O}$, al menos, considerar su papel en la sociedad como «subalterno» , es rasgo del personaje o la posición de su autora. En otras palabras, la idea de que las grandes hazañas transformadoras les están reservadas a las mujeres de la burguesía y no a las emergentes capas medias, ¿podría ser acaso un pensamiento que sostuviese una maestra comprometida? Lo planteo a propósito de esta reflexión de Clarisa:

Estoy conforme aquí. Hay seres cuyo destino es desempeñar siempre en la existencia papeles subalternos. Yo soy uno de ellos. Acepto esa suerte anodina, no merezco más, y comprendo que es sólo sarcasmo de la vida, el despertar a veces en mí un alma rebelde, o un alma ambiciosa, o un alma plena de elegancias espirituales... ¿Para qué necesita todo eso una pobre maestra de escuela rural?26.

Si la educadora no requiere de talento intelectual en tanto desempeña un «papel subalterno», serán los miembros de las elites dominantes los llamados a hacerse cargo de estas críticas.

\section{La expulsión del paraíso}

Donde está el trigo y el vino? (1962) de María Flora Yáñez y La tierra que les di (1963) de Mercedes Valdivieso, coinciden en situar el conflicto de la historia en torno a la muerte de los padres, generándose con ello el problema de la herencia de la tierra por parte de una generación que no sabe producirla ni valorar económica ni emocionalmente su patrimonio. En

\footnotetext{
${ }^{24}$ Abundan también los comentarios deterministas sobre la «raza» del pueblo - sobre todo en voz de Reinaldo-, para explicar las problemáticas de higiene, salubridad y alcoholismo: «Es el mestizaje, Clarisa, el que les lega esa herencia de pereza y de mugre. Ud. olvida que en cada roto asoma un indio», ibidem, p. 29.

${ }^{25}$ Ibidem, p. 81.

${ }^{26}$ Ibidem, p. 11.
} 
estas familias, sus miembros acostumbrados a ser mantenidos por las utilidades que genera la tierra, aspiran a seguir conservando el mismo nivel de ocio y de privilegios sociales $y$ económicos, sin procurar su adecuada administración. Las protagonistas, en tanto, buscan defender su único capital, considerando que carecen de profesión y habilidades para el trabajo, a pesar de sus amplias y sólidas redes sociales. Intentan proteger el latifundio con su extensión original y en condiciones modernizadas de explotación de la tierra; y en su contra, se enfrenta el resto de la familia que, en base a su indiferencia por la gestión y la producción, termina parcelando el predio, vendiendo a bajo costo y perdiendo un bien que se entiende económico, pero sobre todo social y cultural: la forma de vida de la oligarquía chilena.

Estos dos textos están organizados sobre el recuerdo de los días felices, cuando aún existía una sólida estructura patriarcal que sostenía este mundo. La tierra que les di (1963) comienza con los recuerdos de la madre, viuda y enferma, que rememora la tarde en que llega a hacerse cargo de su herencia, junto a su marido. El hermano preferido habría recibido la mayor y mejor parte del terreno, pero años más tarde le vendería su propiedad para aventurarse a conocer la vieja Europa. Tras un arduo trabajo, el matrimonio consigue explotar y cultivar la enorme extensión del latifundio, cumpliendo por fin con su sueño: «La inmensa hacienda primitiva tenía de nuevo un solo dueño» ${ }^{27}$. El recuerdo se concentra de modo reiterado alrededor de la idea del esfuerzo, que comienza con la iniciativa de aumentar el número de trabajadores, lo cual sumado a la constante preocupación de los dueños, termina por asegurar la sumisión de los inquilinos: «Cada campesino que topa es una prolongación de carne que ha aprendido a obedecer por generaciones y que al descubrirse, sigue mostrando el mismo rostro curtido, obscuro, hermético» ${ }^{28}$. Despertando así de sus remembranzas, la mujer descubre a un muchachito tras las rejas de fierro del parque, que le mira de modo insistente:

La señora tiene un estremecimiento: «sentirá hambre. No, no puede ser; aquí en la hacienda todos trabajan». Su pensamiento se tiñe del rojo usado por algún desconocido para escribir en los muros de su casa en la ciudad: «Gobernar es educar» y otras frases semejantes que no recuerda exactamente. "¿Qué es lo que desean?».

Vuelve la cabeza hacia el costado del parque, en donde se levanta la capilla, y se siente tranquila. Hasta alli llegaban siempre las misiones traídas al fundo desde el primer año que tomó posesión de sus tierras y domingo a domingo venía el cura para hacer clases de catecismo y lectura. Además, hacía tres años tuvo que ceder una de sus instalaciones para escuela fiscal, contribuyendo, entonces, con muebles y escritorios. Pero ¿quién respondía de la calidad moral del profesor que llegaría a

\footnotetext{
${ }^{27}$ Valdivieso, Mercedes, La tierra que les di, Editorial Zig-zag, Santiago, 1962, p. 16.

${ }^{28}$ Ibidem, pp. 17-18.
} 
educar a la simple gente del campo, a sus campesinos tranquilos que confiaban en Dios? ${ }^{29}$.

Así, pese a los innegables cambios sociales en el país que afectaron, entre otros, al mundo del agro, estas dueñas insisten en ver en la desaparición de los patriarcas el momento del cambio: «El mundo desapareció cuando él se murió» ${ }^{30}$, dice la señora. Cambios que Oliviala protagonista de Dónde está el trigo y el vino? también vincula a la muerte de su padre ${ }^{31}$.

Las novelas que analizamos se lamentan por la tierra perdida, y con ello la valoración del trabajo que realizaron sus antecesores (varones), la nostalgia por el término de una tradición cultural y social de la casta a la que habrían pertenecido. Los restos de esa tradición se articulan en relación al último heredero que los representa: el padre, quien se entiende como la «columna vertebral» que sostiene un mundo a punto de desaparecer: «Sin saberlo veníamos a esta tierra y a este centro que, por falta de espina dorsal, se derrumbaba»32. Sin el padre fundante, donde «padre», «tierra» y «patria» son una misma cosa, su pérdida viene a significar la expulsión del paraíso: «Lo grave, lo irremediable era otra cosa: haberse despojado de la tierra, vivir en esa muerte tibia que significaba contemplar a diario el paraíso perdido» ${ }^{33}$.

La muerte del padre y la consecuente «caída» son los motivos con que las autoras explican su ingreso al trabajo y a las letras, tal como observamos en la autobiografía literaria de Maité Allamand:

Con el terremoto de 1928, y la tremenda crisis que se desencadenó en esos años, se acabaron el campo, la vida regalada, los estudios, las ilusiones. Destruido por el sismo y la fatalidad el mundo en el que había vivido, era preciso reconstruir otro para poder seguir viviendo. Ya no había dinero para clases de armonía, ni de música, ni ocios para escuchar el parloteo de los pájaros ni las voces típicas y encantadoras de los campesinos. Era preciso ganarse el pan. Entonces, poco a poco, me puse a escribir ${ }^{34}$.

\footnotetext{
${ }^{29}$ Ibidem, p. 24.

${ }^{30}$ Ibidem, p. 30.

${ }^{31}$ Tras su deceso no sólo decae la fecunda vida espiritual de la familia -a su juicio-; además discuten por la gestión del campo hasta entregarlo a un administrador que los lleva a parcelar el terreno, con la amenaza de los «sediciosos comunistas»: "Ya no se pueden tener latifundios, patrona -decía a menudo-. Despiertan la voracidad del populacho. Ustedes mismos me han contado los sustos que pasaron cuando una poblada, hace años, llegó a la hacienda desde Santiago. Los amotinadores pronunciaron discursos, levantaron a los inquilinos y se produjo una verdadera revuelta», ibidem, p. 131. Así, la familia va parcelando el terreno, vendiendo a bajo costo, y perdiendo el gran latifundio, símbolo de su clase.

${ }^{32}$ Yáñez, María Flora, Dónde están el trigo y el vino?, Editorial Zig-zag, Santiago, 1962, p. 149.

33 Ibidem, p. 130.

${ }^{34}$ Allamand, Maité, Quién..., op. cit., pp. 12-13.
} 


\section{La Caída}

Los textos de María Flora Yáñez y Mercedes Valdivieso bien pudieran ser incluidos entre Las novelas de la oligarquía chilena que estudia Grínor Rojo, en tanto presentan un imaginario simbólico que fundamenta la defensa de la clase oligárquica. Rojo, en su libro, analiza seis novelas, cuyo punto de hablada es oligárquico y, la mayor parte de las veces, nostálgico de la pérdida de los principios y atribuciones de su clase, que, por tanto, robustecen su imaginario. Se sostendrían sobre una mitificación de «una época de oro de la casta oligárquica chilena, cuando sus virtudes de fortaleza, empuje y laboriosidad se habrían puesto sobre la mesa con su máxima eficacia y en su máximo esplendor» ${ }^{35}$. Buscarían construir una epopeya de cómo la oligarquía fue «la que hizo Chile» ${ }^{36}$, «edificó la casa chilena e hizo de sus habitantes lo que ellos han 11 gado a ser después» ${ }^{37}$. «El tiempo al que me refiero -afirma Rojo no es otro que el de la construcción del estado nación $\sim$ chileno, con posterioridad a la guerra de la independencia, un desarrollo histórico respecto del cual el grupo oligárquico se autoconsidera su creador y conductor» ${ }^{38}$.

Me parece que las novelas de las autoras que analizamos también se estructuran sobre una nostalgia oligárquica, que atribuye al pasado el carácter de «edad de oro» o «época de gloria», y cuya pérdida justifica el empoderamiento y la liberación de la mujer. Así, la hacienda, en tanto orden incuestionable e incuestionado, se asocia a un patriarcado entendido como «paraíso», anterior a la condición de autonomía y a la división sexual del trabajo. De este modo, las novelas que acá revisamos oscilan entre la nostalgia por este orden y el reconocimiento y valoración de la independencia, posibilitados precisamente por la expulsión de este paraíso o «caída».

La novela La culpa (1964) de Margarita Aguirre, se organiza a partir de la historia de tres miembros de una familia, todos ellos víctimas y herederos de una «culpa» que se remonta a los abusos patronales practicados a comienzos de siglo XX en la hacienda «El Recuerdo». El derecho de pernada ${ }^{39}$, tan común en los fundos chilenos, deviene, en este relato, en el natural nacimiento de un bastardo, tras los encuentros eróticos del hijo del dueño (Ramoncito) con una joven sirvienta. En un comienzo, no hay mayores consecuencias de este embarazo, salvo una insignificante indemnización a la familia, que permite mantener el inalterable orden de las costumbres campesinas. Sin embargo, el contraste entre las prácticas sexuales de hombres y mujeres de la elite, se enciende cuando, ahora, una de las hijas de los patrones (Melania) delata

\footnotetext{
${ }^{35}$ Rojo, Grínor, Las novelas de la oligarquía chilena, Sangría, Santiago, 2011, p. 96.

${ }^{36}$ Idem.

37 Ibidem, p. 97.

${ }^{38}$ Idem.

${ }^{39}$ Sobre las prácticas sexuales de los hacendados recomiendo la lectura del estudio de Valdés, Rebolledo y Wilson, y la interpretación de Rojo, quienes se detienen en el análisis en la novela de Eduardo Barrios, Gran Señor y Rajadiablos, para dar cuenta de las costumbres sociales en el campo, vid. Valdés, Ximena; Rebolledo, Loreto y Wilson, Angélica, op. cit., p. 61, y de la ideología de la oligarquía chilena, vid. Rojo, Grínor, op. cit. Para este último, «echar huachos al mundo» equivaldría en este relato a una «misión civilizadora», un «acto patriótico» de «blanqueamiento de la población del país», ibidem, p. 102.
} 
su avanzado proceso de gestación, a causa de una violación. Del suceso sólo queda la imagen inasimilable de la preñez de una «niña» y de «buena familia». No hay razones que puedan explicar lo inadmisible de esta gravidez y la palabra «violación» no aparece sino hasta dos generaciones después. La familia, entonces, suprime con la expulsión lo que parece amenazar o cuestionar el funcionamiento social de la hacienda: primero, instalando a Melania en un convento y a su vástago en un orfanato; y más tarde, sacando del campo al bastardo de Romancito, por su creciente semejanza física con los patrones. De esta doble violencia, la culpa la pagan, igualados, las mujeres y los campesinos; pero no habiendo condiciones para reparar el daño, la culpa (como el pecado cristiano) emergería irreversiblemente sobre sus descendientes.

De este modo, Marta Figueroa, una joven muchacha de su época (existencialista, crítica de su clase y de su tiempo), se vuelve obsesivamente sobre este oculto secreto de familia. Insiste en encontrar a la tía Melania y en conocer las condiciones de este borramiento familiar, transformándose en la voz que aviva esa culpa. Así, cuando la encuentra en su lecho de muerte, hereda de ella su catre de tísica, su casa destinada al servicio de lavandería y un espacio femenino (con las otras mujeres lavanderas) apropiado -afirma para criar a su hijo huacho, fruto de un fugaz encuentro con un militante comunista. Instalándose en el lugar de Melania, le dedica a su tía muerta unas sentidas palabras en su diario: «El [huacho] redimirá nuestras culpas. Será tuyo y mío y de todos (...) Será de ellas [las lavanderas]: del sufrido y noble pueblo chileno (...) Seguiremos junto a él, lavando, lavando nuestras culpas. Y él crecerá en gracia y sabiduría para darnos, al fin, una vida mejor. Una vida mejor para todos» ${ }^{40}$.

Sus esperanzas en el huacho mestizo y mesocrático, pretenden distanciarse de sus «ilustres antepasados», descendientes de «tribunos y estadistas», por un lado, y «guerreros de la independencia», por el otro. Aunque ella los acusa de ser todos unos locos, ladrones, suicidas, criminales, atribuyendo estas desviaciones al modo de vida de la hacienda, se reserva una indiscutida e intocada versión de perfección para los encomenderos de la Colonia: «Nuestros antepasados fueron criollos sanos, generosos y valientes. Pero nosotros somos pobres tipos, gastados, mediocres, superficiales» ${ }^{41}$, que continúa la mitificación oligárquica hacia los responsables de la construcción del estado nacional chileno ${ }^{42}$.

Así entonces, el discurso libertario de Marta deposita sus esperanzas de un cambio social en los dos descendientes de su familia, mezclados con la sangre del pueblo: el fruto bastardo del

\footnotetext{
${ }^{40}$ Aguirre, Margarita, La culpa, Editorial Zig-Zag, Santiago, 1963, p. 206.

${ }^{41}$ Ibidem, p. 160.

${ }^{42}$ Las razones de por qué estos «buenos tipos» se habrían ido «degenerando», parafrasea, como ya hemos visto, el discurso que la oligarquía había edificado respecto de sí misma, para afirmar su responsabilidad en la construcción del proyecto nacional y su crisis a finales del XIX, con la modernización y sus efectos democratizadores, Rojo, Grínor, op. cit., p. 99. Las demandas sociales habían terminado por evidenciar el contraste entre la «belle époque» de la clase política chilena y las necesidades del pueblo, terminando así por reconocer su caída: «Vengo de una clase social sin redención, que debe desaparecer toda para que la humanidad pueda seguir», ibidem, p. 262, dice Marta, y agrega: «Mis antepasados me dejaron sin fuerza de tanto 'pasarlo bien'», idem.
} 
tío Ramón, "alias El Huacho", y el suyo propio, sucesor del esforzado profesor primario. Del primero se ocupa un abogado, quien sin desconocer el asesinato cometido por su defendido, asegura poder convencer a la sociedad de su inocencia en tanto víctima de "la estructura feudal de nuestra sociedad en crisis a medio derrumbar"43. Lo cual reitera en frases como "la organización caduca de nuestra sociedad" 44 o la "expresión acabada de un orden social de privilegio" 45 , todas ideas tendientes a insistir en el anuncio de un próximo y definitivo término del modelo hacendal. No habría "culpa" heredada en el "Huacho" ni culpa por su asesinato, tras la defensa legal que hace este abogado. La reparación del daño patronal quedaría así subsanada por el aparato jurídico del estado. ¿Pero qué ocurre con la culpa que cargan Melania y su sobrina; que lavan y esperan borrar con el futuro promisorio que depositan en el huacho de Marta? Las culpas de las mujeres no tienen defensa, pareciera insistir la novela.

Si los compañeros de generación de Marta, todos ellos varones de la esforzada clase media, han sabido triunfar como profesionales (médicos, abogados, profesores primarios), luciendo además un discurso crítico que acusa los años de militancia política, lo cierto es que ni sus útiles y rentables profesiones ni sus elaborados discursos parecieran poder dar cuenta de la situación de sometimiento de las mujeres. Pues mientras ellos "son el progreso cultural de la patria" 46 ; ellas, las mujeres burguesas, apenas cuentan con una deficiente formación escolar y escasas herramientas para servir a la sociedad: ni comunista, ni visitadora social, ni asistencialista de obras pías, se lamenta Marta. Ellas, las víctimas (no defendidas) del modelo hacendal, no aparecen en la agenda reivindicativa de ningún discurso libertario ${ }^{47}$.

A pesar de las dificultades y de los esfuerzos de las mujeres por incluirse y ser reconocidas socialmente, Marta logra modelar su propia "revolución social de género", vinculada a superar tabúes de clase: es madre soltera, trabaja como cualquier obrera y le enseña a leer a su primo preso con el fin de insertarlo en la sociedad. Sin embargo, su proyecto se ve interrumpido por dos inesperados motivos: su aparente locura y el, todavía más sorpresivo, asesinato del que es víctima. De estos hechos nos enteramos por voz de su amigo médico, que asume las veces de profesional clínico y de novel escritor. Habiéndola depositado en una clínica psiquiátrica por un cuadro no muy claro de esquizofrenia, histeria y/o hipocondría, una paciente que por allí circulaba, de nombre Eulalia Medina, blande sobre Marta un hachazo que la decapita. La acción además de inesperada se convierte para sorpresa de los allí presentes en un horroroso sacrificio, cuyas causas el médico no alcanza a comprender del todo, a falta de información, pero que en su lectura de entusiasta novelista se

\footnotetext{
43 Ibidem, p. 234.

${ }^{44}$ Ibidem, p. 232.

45 Idem.

${ }^{46}$ Ibidem, p. 293.

47 Marta se lamenta que a pesar de que las mujeres tienen derecho a voto, siguen siendo tratadas como unas niñas por sus familias y la sociedad, en Aguirre, Margarita, op. cit., p. 112.
} 
articulan como un «ciclo redondo, como un aro» ${ }^{48}$, donde las explicaciones oscilan entre lo patológico (la «paranoia obsesiva» de la asesina) y lo imprevisible de la vida y las novelas.

«Soy de los abajo (...) De los que violamos a mansalva. Mi madre fue monja. Crecí en un asilo. Vengo del profundo gusanal de la tierra, del barro, de la sangre oprimida» ${ }^{49}$, así clama Eulalia Medina, la hija ilegítima de Melania, mientras cobra venganza por la violación de su madre, terminando a hachazos con la vida de Marta. Con ello, el «ciclo, redondo como un aro», donde «nada sucede impunemente», «nada queda sin cumplir un papel»50, se cierra para vengar las culpas heredadas. La reparación se vuelve así circularmente sobre ellas, las mujeres, haciendo de esta misma la propia causa de la culpa. La culpa sería así tan estructural al lugar de las mujeres, como la condición misma del «ser mujer» y de su posibilidad. No hay abogado ni marco legal que defienda la culpa femenina; solo un informe médico que sitúa el problema en el orden del trastorno psiquiátrico (focalizado individualmente), o en el ámbito literario, donde el médico se apropia de su interpretación final: «Si la vida de Marta Figueroa fuera una novela, de ella no quedaría más que un retrato histérico, macabro, siniestra profecía de un porvenir deslumbrante» ${ }^{51}$, tal es su defensa.

\section{Las patronas o dueñas de la escritura}

Quisiera concluir con la novela Páramo salvaje (1963) de María Elena Gertner, la cual, me parece, da un giro respecto a lo que hemos visto hasta aquí, en tanto se aleja del imaginario oligárquico. La hacienda esta vez está ubicada en los límites cordilleranos entre Chile y Argentina y ni su clima ni el ambiente pretenden la aparente placidez de las anteriores. Si la novela de Aguirre se instala sobre «El Recuerdo» de «culpas» y vagas idealizaciones de antepasados lejanos, en este relato el pasado se remonta apenas una generación hacia atrás y la misma composición familiar acusa desviaciones y vacíos que impiden cualquier idealización de plenitud «pequeño burguesa». Francisco, propietario de la hacienda «Páramo salvaje» y padre de dos hijos, frutos de un primer matrimonio, forma una segunda relación con Olga, madre a su vez de Catalina, la protagonista. La nueva pareja suma a esta descendencia un cuarto hijo en común, quienes por siete años viven en la hacienda, hasta que Olga decide marcharse con un nuevo amor, aparentemente más joven. El marido traicionado muere ipso facto de un infarto, con lo cual estos cuatro jóvenes huérfanos se ven de pronto asumiendo el mando del fundo.

Me interesa focalizarme en el modo en que la protagonista Catalina termina haciéndose cargo de su administración. Para ello, ha ido elaborando (a lo largo de la historia) un discurso subversivo que pone en cuestionamiento la moral cristiana y el modelo hacendal, ambos entrañablemente unidos en su organización patriarcal. Este cambio de perspectiva supone, en primer lugar, replantearse la lectura tradicional respecto de las herencias familiares. Si en las

\footnotetext{
48 Ibidem, p. 341.

49 Ibidem, p. 340.

50 Ibidem, p. 341.

${ }^{51}$ Ibidem, p. 338.
} 
novelas anteriores las protagonistas oscilaban entre las nostalgias oligárquicas, la crítica a los abusos patriarcales y a la «culpa» que irremediablemente se vuelve contra las mujeres y su descendencia, Catalina, en cambio, libra a la madre de las culpas que le atribuyen sus hermanos e interpreta en sus acciones una muestra de valentía digna de admiración. Tal es así que decide prolongar «las tradiciones implantadas por la madre» ${ }^{52}$, lo cual significa no sólo valorar positivamente los actos de ella, sino asumir una herencia matrilineal, que se desentiende de la tradición masculina patriarcal. Así, cuando analiza su lugar de liderazgo en la hacienda (junto a Ignacio, su hermanastro y amante), el rol de «patrona» (en femenino), que según Ignacio definiría el «ejemplo de lo que debe y no debe hacerse» ${ }^{53}$, supondría una conducta piadosa, que asiste a misa y confesión. Pero si «al hombre no se le exige lo que a la mujer» ${ }^{54}$-argumenta Catalina , pues nadie esperaría «que el patrón sea un modelo de virtudes» ${ }^{55}$, ella, como «patrona» rehúsa entonces a ser asociada a ese modelo de virtud que impone la iglesia católica. De este modo, pone en discusión la moral cristiana, reprochándole su sexismo en la división de los roles de género. Mientras ella y sus inquilinos cruzan la frontera a caballo, luego de varios días en la montaña, Catalina se pregunta de pronto y en voz alta «cómo son las mujeres», recibiendo, sin pedirlo, la respuesta de uno de sus peones: «Los ojos de la mujer deben cerrarse y abrirse bajo techo, amasando el pan y meciendo a los chiquillos, y no a campo traviesa» ${ }^{56}$. Catalina se queda un buen rato digiriendo las palabras del trabajador y al llegar al fundo entra a la capilla y así le habla a Dios:

[Amasar el pan y mecer chiquillos] «es el premio que reservas a las que saben obedecerte (...) $Y$ a las otras, a las rebeldes, a las que te desafían... ¿qué les das? Sí, ya sé. Las condenas a la soledad. Sin pan que amasar ni cunas para mecer. Pero... ¿es nuestra toda culpa?, ¿es mía? Si yo hubiera nacido hombre, quizás me habrías dado otras posibilidades. Claro, al hombre siempre le reservas los caminos amplios, las grandes hazañas. Para encarnarte no elegiste la forma de una mujer, sino la de un hombre. (...) tu Iglesia está edificada sobre un hombre, por ellos y para ellos. A la mujer, en cambio, la hiciste salir de un costado de Adán, y cualquier camino estará para ella marcado y limitado por la grandeza o la miseria del hombre» 57.

La claridad de su lectura le impide, no obstante, librarse de llevar un camino «marcado por la grandeza o miseria del hombre» que, en su caso, se traduce en la fidelidad y dependencia

\footnotetext{
${ }^{52}$ Gertner, María Elena, Páramo Salvaje, Editorial Zig-zag, Santiago, 1963, p. 36.

${ }^{53}$ Idem.

${ }^{54}$ Idem.

${ }^{55} \mathrm{Idem}$.

${ }^{56} \mathrm{Ibidem}, \mathrm{p} .132$.

${ }^{57}$ Idem.
} 
hacia Ignacio. Sólo con su muerte, Catalina, que habiendo vivido la mayor parte del tiempo sola en el fundo, asume ahora formalmente su mando, reparando las innumerables arbitrariedades $\mathrm{y}$ violencias cometidas bajo la administración de su hermanastro ${ }^{58}$.

Si bien en casi todas las novelas hay un cuestionamiento explícito de la administración de los patrones de los fundos -sea en términos económicos, sociales, como en materia de género , haciéndose eco de la crítica sostenida durante toda la primera mitad del siglo XX respecto al estancamiento de la agricultura, hay también un evidente deseo de parte de las protagonistas de asumir las riendas de la gestión del campo. Al lado de sus maridos y/o administradores, supervisan la inversión, el uso de tecnologías agrícolas, el bienestar de los trabajadores, intentando demostrar su idoneidad en términos de liderazgo, que en ningún caso pretende desmontar el viejo sistema del latifundio, tan discutido ya para comienzos de los '60, sino recuperarlo para sí mismas. Ante el vacío generado por la muerte del padre, o la ausencia del dueño, que desmorona el caduco sistema hacendal patriarcal, la mujer burguesa así como ve borrarse el privilegiado espacio de la inocencia y dependencia, vislumbra también la estructura que fundamenta el lugar de su sumisión. En tanto «desheredada» y «expulsada del paraíso» comprende la «culpa» que entraña la caída, constitutiva del propio modelo hacendal patriarcal. De estas ruinas surge su incipiente conciencia de autonomía que experimenta de distintas maneras: una valoración por el trabajo y la independencia económica (Clarisa y Marta), aunque se critique la precarización del trabajo femenino; un deseo de liderar modelos económicos y sociales más justos (Catalina), sólo posible sobre la base de una mirada descreída e irónica respecto de los papeles masculinos; y una legitimación de la escritura que les permita hacerse «dueñas» de los discursos (Allamand) ${ }^{59}$.

La crítica y destrucción del modelo hacendal, que exige una democratización de la estructura social con consignas como «la tierra para el que la trabaja», ha visibilizado a lo largo del siglo XX el sometimiento y violencia hacia el "pueblo», hasta llegar a los'60 con una clara disposición de reforma del agro. Mientras tanto, las mujeres han orientado sus propias demandas en la participación ciudadana con derechos laborales, de educación y el voto

\footnotetext{
${ }^{58}$ Éste, como el resto de los patrones, habría hecho uso y abuso del derecho de pernada, sin apoyar moral ni económicamente a la mujer embarazada. Presionado por la familia de la joven a la que ha preñado -la que espera una ayuda material-, resuelve asesinar sin más al padre de la muchacha. En el plano de la producción, muy tempranamente habría dejado de cultivar la tierra para dedicarse exclusivamente al contrabando de animales, evitando además ofrecer trabajo y remuneración a sus empleados. Catalina, entonces, cuando asume la administración, hace un giro radical en el tipo de gestión: se acerca en primer lugar a la mujer del hijo bastardo para ofrecer su ayuda, opta por el cultivo de la tierra y por el bienestar de los trabajadores.

${ }^{59}$ Me refiero al primer libro de cuentos de Maité Allamand, Cosas de campo (1935), en que la autora crea un escenario de ingenuas fantasías y leyendas rurales, cuyos personajes, al finalizar la compilación, se acercan a esta escritora, a la que llaman la «patroncita», para agradecerle (los menos) y recriminarle (los restantes) las infidencias de sus ficciones. «¿Cuáles son los límites de la realidad? ¿En dónde termina o empieza la ficción?», Allamand, Maité, Cosas de campo, Imprenta cultura, Santiago, 1935, p. 112, concluye por preguntarse la novel escritora. Frustrada en su deseo de representar a los «otros», esta "patroncita» asume autocríticamente el fallido intento por sostener, por voz femenina, un mundo patronal idealizado: la «realidad» de sus personajes se vuelve contra la autora-patrona para reclamarle el modo en que han sido interpretados.
} 
político. A pesar de ello, estas reivindicaciones no devienen necesariamente en una integración de la mujer en condiciones de igualdad, en la medida que se continúa imponiendo el modelo de la diferencia sexual.

Las novelas que analizamos buscan, en cambio, adentrarse en los fundamentos que instituyen esa diferencia, volviéndose hacia el latifundio -del mismo modo que los trabajadores , para encontrar allí la «columna vertebral» que fundamenta económica y religiosamente el discurso patriarcal. Con capillas y misiones en todas las haciendas, el discurso cristiano había servido para mantener estable esta división social entre patrones y trabajadores. Las mujeres, aparentemente del lado de los «patrones», pero limitadas a ser meras «costillas», van evidenciando que no basta con destruir el «modelo hacienda» ni los fundamentos de la moral cristiana para su integración, pues con ello no se hacen necesariamente poseedoras de la tierra, ni dueñas de sus vidas con trabajo y educación. La herencia de una culpa atribuida al género y a una clase, apuntaría a su reproducción, donde el único acto de liberación (ni el sexo, ni los abortos, ni los niños huachos), consistiría en contar la propia historia para volverse «patrona/dueña» de las significaciones sociales y los bienes simbólicos, y «patrona/modelo» de nuevos valores. 


\section{Bibliografía}

- Aguirre, Margarita, La culpa, Editorial Zig Zag, Santiago, 1963.

- Allamand, Maité, Cosas de campo, Imprenta cultura, Santiago, 1935.

- — Parvas viejas, Imprenta cultura, Santiago, 1936.

- — Huellas en la ciudad, Editorial Pacífico, Santiago, 1966.

- — Quién soy, Editorial Nascimento, Santiago, 1982.

- Barros, Luis y Vergara, Ximena, El modo de ser aristocrático. El caso de la oligarquía chilena hacia 1900 (1978), Ariadna Ediciones, Santiago, 2007.

- Bengon, José, Historia Rural de Chile central. Tomo 1 y 2, Editorial LOM, Santiago, 2015.

- Bombal, María Luisa, La última niebla, Nascimento, Santiago, 1934.

- Cereceda, Luz Eugenia y Dahse, Fernando, Dos décadas de cambios en el agro chileno, Alfabeta impresores, Santiago, 1980.

- Cisterna, Natalia, Entre la casa y la ciudad. La representación de los espacios público y privado en novelas de narradoras latinoamericanas de la primera mitad del siglo XX, Editorial Cuarto Propio, Santiago, 2016.

- Chonchol, Jacques, Sistemas agrarios en América Latina. De la etapa prehistórica a la modernización conservadora, Fondo de Cultura Económica, Santiago, 1996.

- DolL, Darcie, «Escritoras chilenas de la primera mitad del siglo XX: trayectoria en el campo literario y cultural como criterios para una periodización de su producción». Taller de Letras, 54, 2014 (pp. 23 38).

- Egaña, María Loreto; Núñez Prieto, Iván; Salinas Álvarez, Cecilia, La educación primaria en Chile: 1860 1930. Una aventura de niñas y maestras, LOM PIIE, Santiago, 2003.

- Gertner, María Elena, Páramo Salvaje, Editorial Zig zag, Santiago, 1963.

- Godoy Catalán, Lorena; Díaz Berr, Ximena, y Mauro Cardarelli, Amalia, «Imágenes sobre el trabajo femenino en Chile, 1880 2000», Universum, 24, 2, 2009 (pp. 74 93)

- Gómez, Sergio y Echeñilue, Jorge, La Agricultura Chilena: las dos caras de la modernización, Ed. FLACSO/AGRARIA, Santiago, 1988.

- Kay, Cristóbal, «Política Económica, Alianza de Clases y Cambios Agrarios en Chile». Economía, 3, 5, 1980 (pp. 125 160).

- Hutchison, Elizabeth, «La historia detrás de las cifras: la evolución del censo chileno y la representación del trabajo femenino, 1895 1930». Historia, 33, 2000 (pp. 417 434). 
, Labores propias de su sexo. Género, políticas y trabajo en Chile urbano 1900 1930. LOM, Santiago, 2006.

- Illanes, María Angéliza, Cuerpo y sangre de la política. La construcción histórica de las Visitadoras Sociales (1887 1940), LOM, Santiago, 2006.

- Kinkwood, Julieta, Ser política en Chile. Las feministas y los partidos (1986), Editorial Cuarto Propio, Santiago, 1990.

- Kotтow, Andrea, «Feminismo y femineidad: escritura y género en las primeras escritoras feministas en Chile», Atenea, 508, 2013 (pp. 151 169).

- Lavrin, Asunción, Mujeres, feminismo y cambio social en Argentina, Chile y Uruguay 1890 1940, Centro de Investigación Diego Barros Arana, Santiago, 2005.

- Mellafe, Rodolfo, «Latifundio y poder rural en Chile de los siglos XVII y XVIII», Cuadernos de Historia, 1, 1981 (pp. 87 108).

- OlEa, Raquel, «Escritoras de la generación del cincuenta. Claves para una lectura política», Universum, 25, 2010 (pp. 101 116).

- Oszlak, Oscar, La trama oculta del poder. Reforma agraria y comportamiento político de los terratenientes chilenos, 1958 1973, LOM USACh, Santiago, 2016.

- $\quad$ ReYes, Chela, Tía Eulalia, Editorial Rapa Nui, Santiago, 1950.

- Rojo, Grínor, Las novelas de la oligarquía chilena, Sangría, Santiago, 2011.

- $\quad$ SalazAr, Gabriel, Labradores, peones y proletario, LOM, Santiago, 2000.

- Valdés, Ximena; Rebolledo, Loreto y Wilson, Angélica, Masculino y femenino en la hacienda chilena del siglo XX, Fondart, Santiago, 1995.

- VAldivieso, Mercedes, La tierra que les di, Editorial Zig Zag, Santiago, 1962.

- YÁñez, María Flora, El abrazo de la tierra, Imprenta Universitaria, Santiago, 1933.

- $\quad$ Espejo sin imagen, Editorial Nascimento, Santiago, 1936.

- $\quad$ Las cenizas, Editorial Tegualda, Santiago, 1949.

- _ L L La Piedra, Editorial Zig Zag, Santiago, 1952.

- _ _ Dónde están el trigo y el vino?, Editorial Zig Zag, Santiago, 1962. 